\section{Förderpreis der Sektion Kopf-Hals 2021}

Die Sektion Kopf-Hals der DEGUM schreibt auch für 2021 den Förderpreis der Sektion aus. Der Preis ist mit 500 Euro dotiert und richtet sich an Wissenschaftler der KopfHals-Sonografie, die sich mit außergewöhnlichen Publikationen oder einer Habilitationsschrift der Kopf-Hals-Sonografie verdient gemacht haben.

Autoren, die bereits den DEGUM-Preis verliehen bekommen haben, können sich nicht ein zweites Mal bewerben. Es ist jedoch möglich, dass eine abgelehnte Arbeit im Folgejahr erneut eingereicht wird.

Der Antrag ist formlos auf elektronischem Weg unter Anlage der eingereichten Publikation bis zum 30. April 2021 an die DEGUM-Geschäftsstelle (DEGUM e. V., Charlottenstr. 79/80, 10117 Berlin, geschaeftsstelle@degum.de) zu richten.
Die Preisverleihung erfolgt während des Treffens der Sektion Kopf-Hals im Herbst 2021. Die Anwesenheit des Preisträgers ist hierbei obligat. Im Rahmen der Preisverleihung wird der Preisträger bzw. die Preisträgerin aufgefordert, seine bzw. ihre Arbeit in einem Kurzreferat vorzustellen. 